\title{
The Relationship between Anterior Tubercle of the Atlas to the Adjacent Oropharyngeal Airway Volume: Implication of Normalized Variables and Gender Differences
}

\author{
Yamazaki $\mathrm{Y}^{1}$, Shigeta $\mathrm{Y}^{\star 2}$, Ogawa $\mathrm{T}^{2}$, Enciso $\mathrm{R}^{3}$, Ando $\mathrm{E}^{2}$, Ikawa $\mathrm{T}^{2}$, Hosoya $\mathrm{N}^{1}$ and Clark $\mathrm{GT}^{4}$ \\ ${ }^{1}$ Department of Endodontology, School of Dental Medicine, Tsurumi University, Yokohama, Japan \\ ${ }^{2}$ Department of Fixed Prosthodontic Dentistry, School of Dental Medicine, Tsurumi University, Yokohama, Japan \\ ${ }^{3}$ Division of Craniofacial Sciences and Therapeutics, School of Dentistry, University of Southern California, Los \\ Angeles, USA \\ ${ }^{4}$ Orofacial Pain/Oral Medicine Center, Division of Diagnostic Sciences, School of Dentistry, University of Southern \\ California, Los Angeles, USA
}

${ }^{*}$ Corresponding author: Shigeta Y, DDS, Ph D, Department of Fixed Prosthodontic Dentistry, School of Dental Medicine, Tsurumi University, Yokohama, Japan, 230-8501, Fax and Tel: +81-45-580-8417, E-mail: Shigeta-y@tsurumi-u.ac.jp

Citation: Yamazaki Y, Shigeta Y, Ogawa T, Enciso R, Ando E, et al. (2016) The Relationship between Anterior Tubercle of the Atlas to the Adjacent Oropharyngeal Airway Volume: Implication of Normalized Variables and Gender Differences. J Dent Oral Care Med 2(1): 107. doi: 10.15744/2454-3276.2.107

Received Date: December 04, 2015 Accepted Date: February 09, 2016 Published Date: February 10, 2016

\begin{abstract}
Objectives: To examine a group of 38 Japanese males and females (group matched by age and body mass index) for changes of the anterior tubercle of atlas region and the posterior parapharyngeal wall with increasing age and body mass index.

Methods: Volumes were measured in Computerized Tomography scans with commercial software and compared between genders. Results: There were statistically significant differences between genders in anterior tubercle height, volume (ATV) and posterior pharyngeal wall volume but once we adjusted these measurements for patient's height, these differences were not found significant. In this study, the anterior tubercle volume (normalized by patient's height) increased with age in both groups after adjusting for BMI. The posterior pharyngeal wall volume (normalized by patient's height) decreased with age in males while it increased with BMI in females. Finally, the AP measurement of the cross-section of the airway at the most prominent point of the anterior tubercle decreased in females with an increase of ATV and ATV/height.
\end{abstract}

Conclusions: In this study there is evidence that enlargement of the anterior tubercle of the atlas occurs with age and the adjacent posterior pharyngeal wall volume increases in a statistically significant fashion with BMI though further research is necessary to prove if it is clinically relevant. An enlargement of the ATV was correlated with a decrease in AP dimension of the airway in females, which has been associated in prior studies with Obstructive Sleep Apnea.

Keywords: Anterior Tubercle of Atlas; Computerized Tomography; Oropharyngeal airway; Posterior pharyngeal walls

\section{Introduction}

Vertebral degeneration includes narrowed intervertebral disc space, osteophyte formation, end-plate sclerosis and irregularity, and Schmorl's node formation [1]. In the cervical region, osteophyte formations have been reported on two obstructive sleep apnea patients where a large altlas osteophyte appeared to be compromising the adjacent oropharnygeal airway space (Figure 1) [2]. Osteophytes of the cervical spine are usually seen in elderly adults and when they are particularly prominent, they have been blamed for inducing dysphagia, cough, dysphonia and dyspnea [3-6].

In 2009, Ando, et al. reported on an Obstructive Sleep Apnea (OSA) patient with cervical spinal osteophytes, which is regarded as one of the causes of airway obstruction. In this case report, the X-ray image revealed the presence of large osteophytes or sclerotic enthesopathy, lying on anterior surfaces from the fourth to seventh cervical vertebrae [7]. Furthermore, in the reconstructed threedimensional image, the airway appeared displaced to the right of the cranio-mandibular bone, with the hyoid bone displaced in the same manner to that of the airway. The spine also appeared displaced to the left side of cranio-mandibular bone. From these findings, they suggested that the cervical spinal osteophytes are one potential cause of airway obstruction. In addition, there are several case reports which regard OSA patients with cervical spinal osteophytes, as one of the causes of airway obstruction [8,9]. 

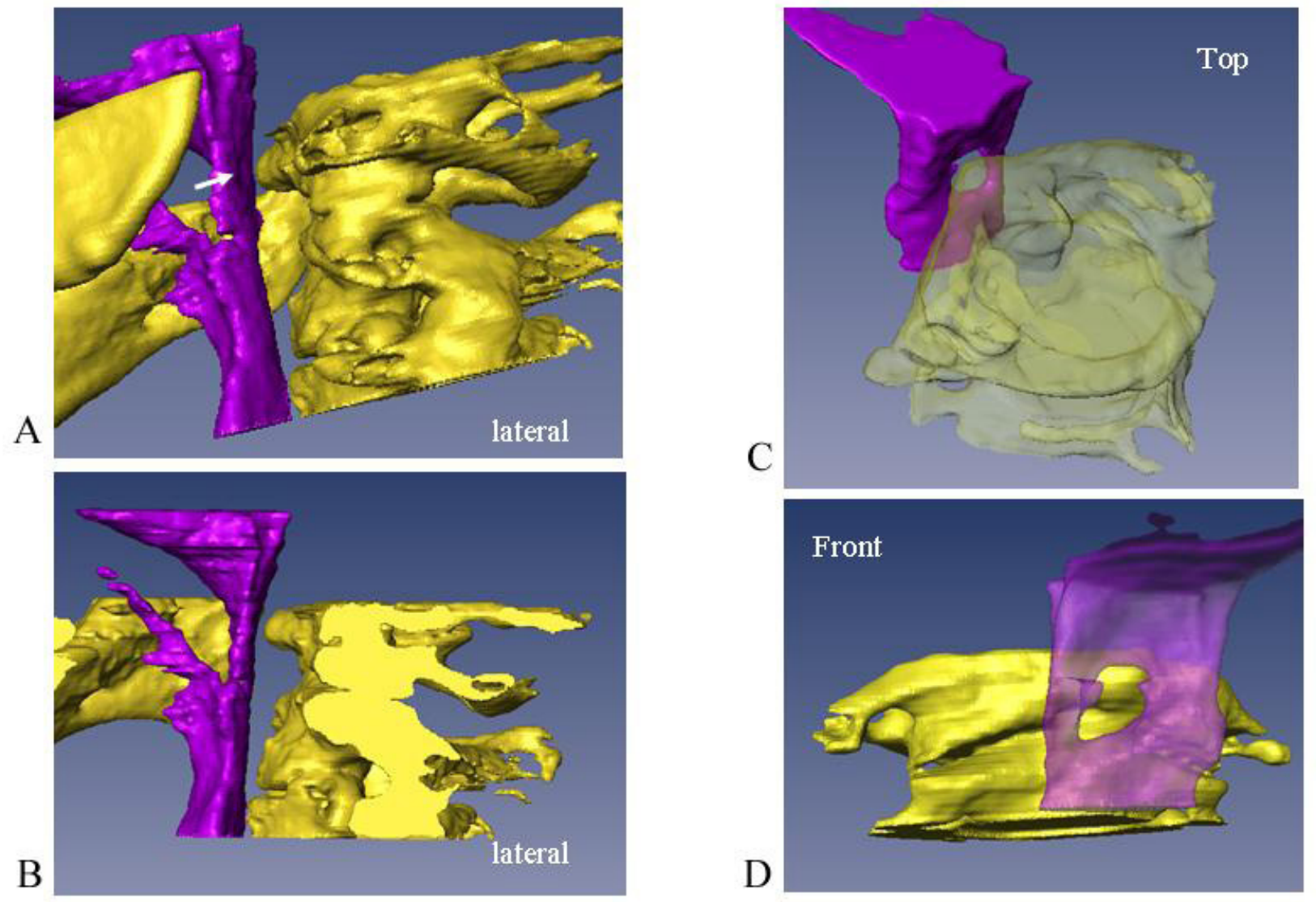

Figure 1: Two patients with large anterior atlas (C-1 or cervical 1) tubercles which either impinge on the airway (A and B represent two slightly different viewpoints of the upper airway region of patient 1 ), or divided it in two (C represents a view from the top and $\mathrm{D}$ a frontal view of the upper airway region) [2]

In a previous study to investigate the potential link between OSA and the calcification of ligaments, the prevalence of the calcification of ligaments in OSA patients and the relationship between these findings, and OSA severity were examined [10]. They reported that there was a significant positive correlation between the severity of OSA and the calcification of the nuchal ligament, before and after, adjusting for BMI. The prevalence of the calcification of the nuchal ligament, in OSA subjects and snorers, was higher than in previous studies with non-OSA subjects. Consequently, they suggested that the severity of OSA correlates with the presence of calcification of the nuchal ligament.

The mechanism underlying osteophyte formation was examined by Kumaresan, et al. who performed the dynamic analysis of cervical spine using finite element modeling [11]. They found that the strain energy density and stress in vertebral cortex increased adjacent to the degenerated disc, especially the anterior region and speculated that over time this may induce osteophytes formation. Solow, et al. suggested that the increase in the diameters of airway, due to extension of the cranio-cervical angle and forward head posture, reflects a compensatory physiological postural mechanism to maintain airway adequacy in OSA patients [12]. In 2015, Shigenoto, et al. suggest that OSA patients have a tendency to change their head posture, to increase the airway width, which can influence cervical curvature [13]. The prevalence of the calcification of ligaments in OSA patients may be associated with the head position.

The atlas has the anterior tubercle for the attachment of the Longus colli muscles and the anterior longitudinal ligament, and is responsible for the nodding and rotation movements of the head. Therefore, in OSA patients with wide cervical angles, it is considered that the morphologic change may occur in the atlas. However, there was no report that focused specifically on the atlas.

In this paper, we examined 38 CT's (19 males and 19 females group matched by body mass index and age) for differences regarding their anterior tubercle volume (ATV), the adjacent airway volume (the region anterior to the tubercle) or the anterior-posterior (AP) and lateral dimensions (LW) of the airway at the cross-sectional slice which corresponds to the most anterior point in a midline sagittal view of the anterior tubercle (shown in Figure 2). In a secondary analysis, we studied these data for the influence of age and body mass index (BMI) on the anterior tubercle of atlas region using linear regression analysis. 


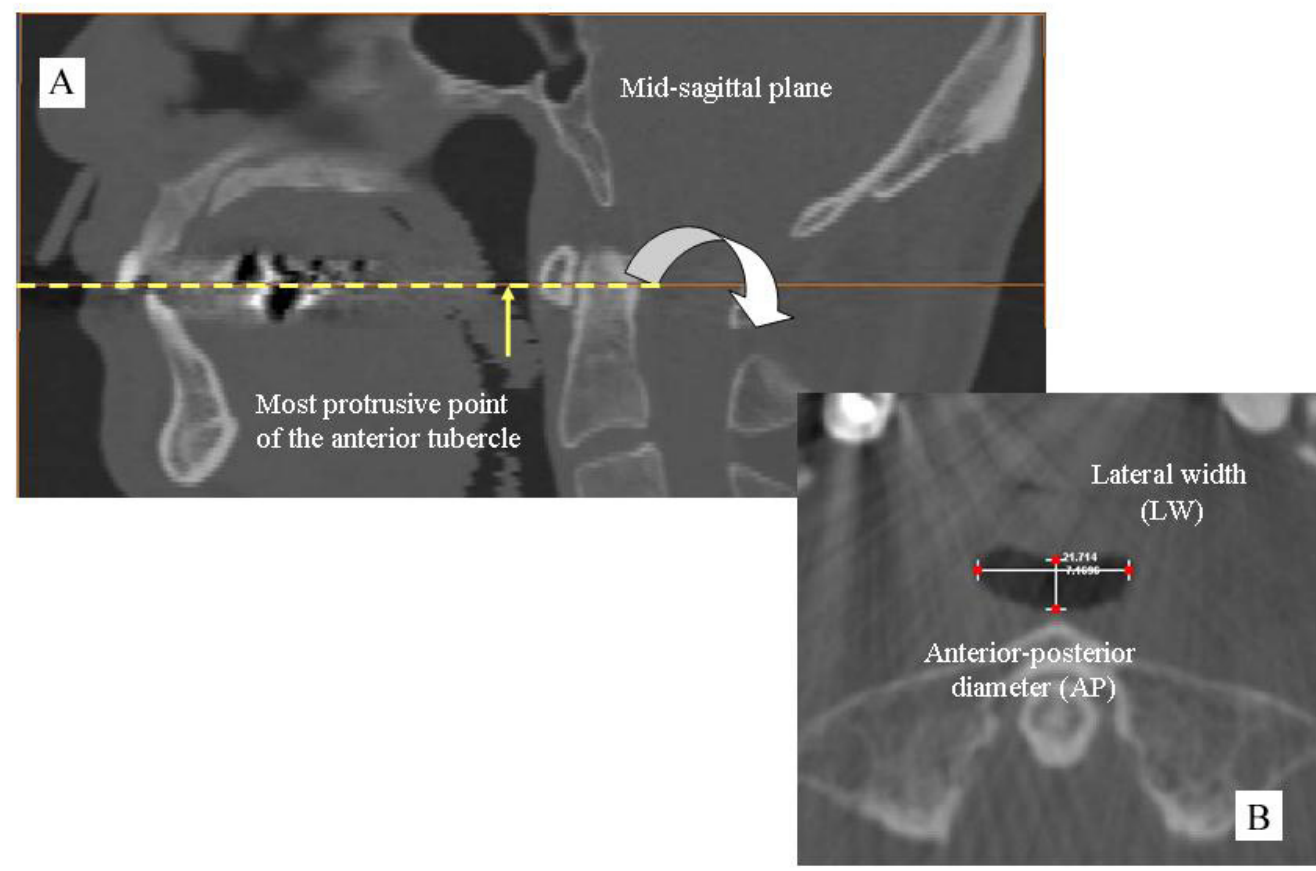

Figure 2: A: Localization of the most protrusive point of the anterior tubercle on the sagittal plane (midline)

B: Measurement of anterior-posterior diameter (AP) and lateral width (LW) of the airway on axial plane defined as in A

\section{Subjects and Methods}

\section{Subjects}

In this retrospective study, records for consecutive patients in need of a spiral CT at the Tsurumi university dental hospital were studied. Patients, who had spiral CT's taken to further examine their maxillofacial and cervical structures as part of their diagnostic assessment, were selected to have an exact match on gender and frequency matching on age and BMI. The survey period was from June, 2005 to March, 2007.

The patients gave written consent to participate in this study approved by the Ethics Committee at Tsurumi university dental hospital.

\section{Device and Software}

The spiral CT imaging of the airway was performed using a Radix Prima (Hitachi Medical Co., Tokyo, Japan). The parameters used for the imaging were tube voltage $=120 \mathrm{kV}$; tube current $=75 \mathrm{~mA}$; irradiation time $=1 \mathrm{~s}$; scan $=$ volume scan; slice thickness $=1$ $\mathrm{mm}$; table speed $=1 \mathrm{~mm} / \mathrm{s}$. From the resulting data, the airway was extracted using image analysis software Amira 3.1 (Mercury Computer Systems / 3D Viz group, San Diego, CA) to reconstruct three-dimensional images and to measure the anterior tubercle of the atlas, posterior pharyngeal wall and the airway volumes as shown in Figure 3 Segmentation was performed automatically based on brightness values (see below).

\section{Investigation items}

Our area of interest was established using 21 sagittal slices with 10 slices on both sides of the mid-sagittal slice of the anterior tubercle (Figure 3B). We measured the ATV, the AT airway volume and the posterior pharyngeal wall volume between the superior and inferior edges of the anterior tubercle (Figure 3A). The ATV was calculated from the number of voxels that included the CT value range from 400 Hounsfield units (HU) to a maximum value (bone CT value: 1000) (the inside area (bone marrow) was filled). The AT airway volume was calculated from the number of voxels that included the CT value range from a patient-specific minimum value to -200 (air CT value: -1000). The posterior pharyngeal wall volume was calculated from the number of voxels that included the CT value range from -200 HU to a maximum value to include all soft tissues (muscle CT value: $30-60 \mathrm{HU}$, fat tissue CT value: -100) except the bone. The number of axial slices between the superior and inferior edges of the anterior tubercle in midsagittal view (defined as AT height) was different by individual. Each volume was normalized by the patient's height to compensate for differences in height between patients. The most anterior point of the anterior tubercle in mid-sagittal view defined which horizontal slice was selected to measure the smallest AP and widest LW measurements of the airway (Figure 2). 


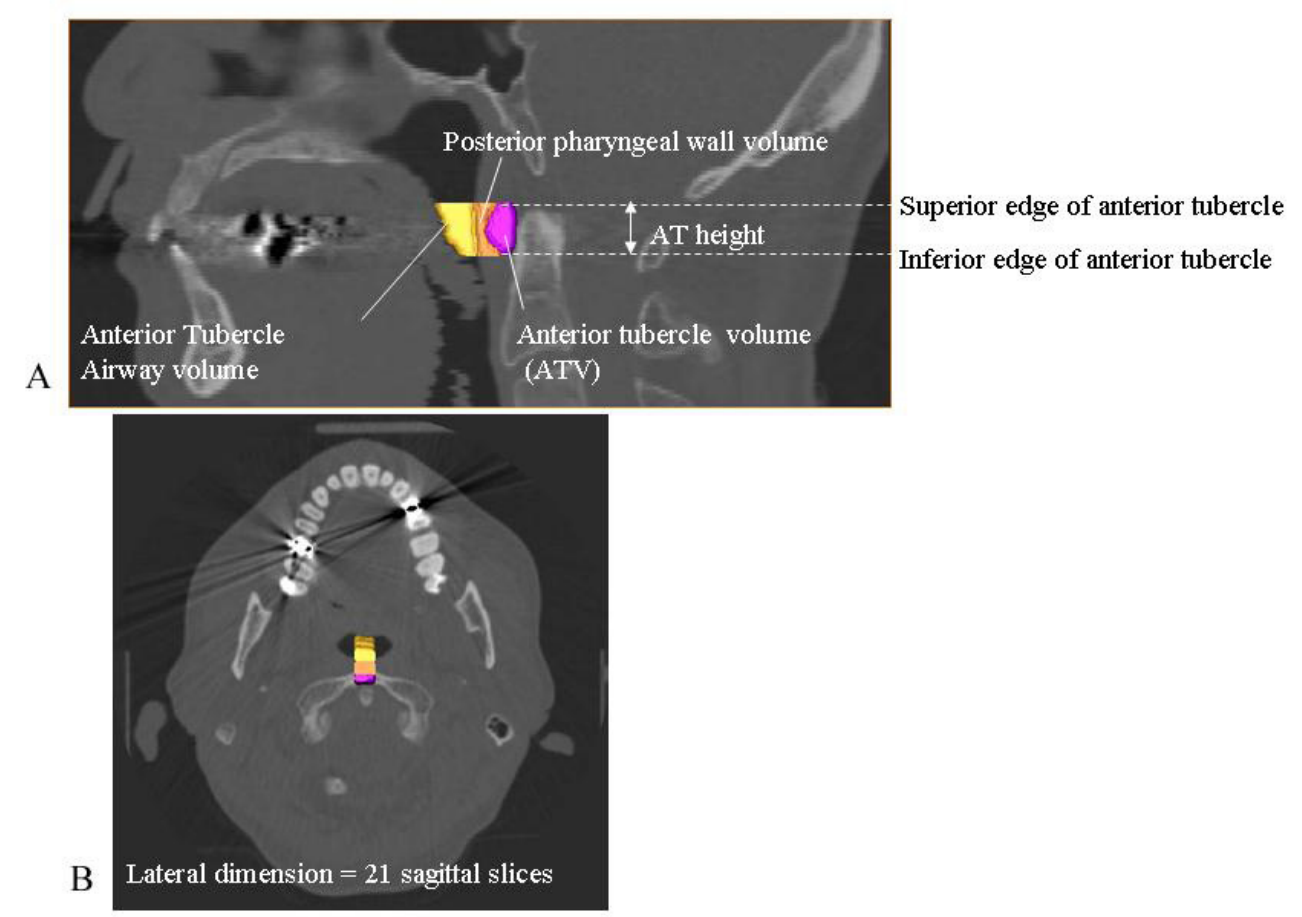

Figure 3: A: Region of interest is defined in a mid-sagittal view between superior and inferior edge of the anterior tubercle of the atlas. Then, the anterior tubercle volume (ATV), anterior tubercle airway volume and posterior pharyngeal wall volume were calculated

B: Lateral dimension of the AT region is arbitrarily defined as equal to 21 slices for every patient centered at mid-sagittal

\section{Statistical analysis}

Descriptive statistics in Tables 1 and 2 correspond to means and one standard deviation of our variables. To compensate for the fact that in general males are larger than females, we normalized AT volume, AT airway volume and the parapharyngeal posterior wall volume by patient's height. Variables normality was tested by the formal Kolmogorov-Smirnov test. Three anatomical variables did not pass the normality test (AT height, posterior wall volume and normalized posterior wall volume). We used the independent $\mathrm{t}$-test two-tailed (alpha $=0.05$ ) to compare men and women's anterior tubercle volume, airway volume, normalized volumes, $\mathrm{AP}$, LW, and covariates (age, BMI). We compared men and women anterior tubercle height, posterior wall volume and normalized posterior wall with Mann-Whitney U-test. We used Pearson's correlation test to study the relationship between our continuous normal variables and Spearman's for the non-parametric. We investigated the linear relationships with linear regression and the model successfully satisfied the assumptions of normality, linearity and homoscedasticity of the residuals. Statistical analysis was carried out by SAS (SAS Institute Inc. Cary, NC, USA) with significance value of 0.05 .

\begin{tabular}{|c|c|c|c|}
\hline Variable & Men $(\mathbf{n}=\mathbf{1 9})$ mean \pm one s.d. & Women $(\mathbf{n}=\mathbf{1 9})$ mean \pm one s.d. & Independent t-test $\mathbf{p}$ value \\
\hline Age $($ years $)$ & $53.5 \pm 16.12$ & $51.1 \pm 17.29$ & 0.658 \\
\hline BMI $\left(\mathrm{kg} / \mathrm{m}^{2}\right)$ & $22.6 \pm 2.38$ & $21.9 \pm 3.67$ & 0.447 \\
\hline Height $(\mathrm{mm})$ & $1676.3 \pm 52.62$ & $1560.2 \pm 60.42$ & $<.0001$ \\
\hline
\end{tabular}

Table 1: Baseline comparison for men and women

\begin{tabular}{|l|c|c|c|}
\hline Variable & Men $(\mathbf{n}=\mathbf{1 9})$ mean \pm one s.d. & Women $(\mathbf{n}=\mathbf{1 9})$ mean \pm one s.d. & p value \\
\hline Anterior tubercle height $(\mathrm{mm})$ & $11.95 \pm 1.54$ & $10.6 \pm 1.71$ & $\mathbf{0 . 0 1 6} \neq$ \\
\hline Anterior tubercle volume $\left(\mathrm{ATV} ; \mathrm{mm}^{3}\right)$ & $621.1 \pm 99.58$ & $523.4 \pm 155.91$ & $\mathbf{0 . 0 2 7}$ \\
\hline Anterior tubercle airway volume $\left(\mathrm{ATAV} ; \mathrm{mm}^{3}\right)$ & $1166.9 \pm 383.81$ & $1080.8 \pm 219.39$ & 0.403 \\
\hline Posterior airway wall volume $\left(\mathrm{PPWV} ; \mathrm{mm}^{3}\right)$ & $532.6 \pm 199.95$ & $396.6 \pm 186.65$ & $\mathbf{0 . 0 1 8} \neq$ \\
\hline ATV / height $\left(\mathrm{mm}^{2}\right)$ & $0.37 \pm 0.58$ & $0.34 \pm 0.11$ & 0.242 \\
\hline ATAV / height $\left(\mathrm{mm}^{2}\right)$ & $0.70 \pm 0.23$ & $0.69 \pm 0.15$ & 0.994 \\
\hline PPWV/ height $\left(\mathrm{mm}^{2}\right)$ & $0.32 \pm 0.12$ & $0.26 \pm 0.13$ & $0.075 \ddagger$ \\
\hline Airway anterior-posterior diameter $(\mathrm{mm})(\mathrm{AP}) \dagger$ & $9.1 \pm 3.11$ & $9.6 \pm 3.16$ & 0.652 \\
\hline Widest airway lateral width $(\mathrm{mm})(\mathrm{LW}) \dagger$ & $20.5 \pm 5.28$ & $25.6 \pm 7.02$ & $\mathbf{0 . 0 1 5}$ \\
\hline
\end{tabular}

¥ Mann-Whitney U-test due to non-normality of data

$\dagger$ Smallest AP and widest lateral dimensions of airway cross-section at the most anterior point in a midline sagittal view of the anterior tubercle (Figure 2B)

Table 2: Comparison of each parameter in men and women (independent $\mathrm{t}$-test). Bold $\mathrm{p}$-values are statistically significant $(\mathrm{p}<.05)$ 


\section{Results}

38 Japanese patients (male: 19, female: 19) who had spiral CT's taken to further examine their maxillofacial and cervical structures as part of their diagnostic assessment were selected to have an exact match on gender, and frequency matching on age and BMI (independent t-test: age $\mathrm{p}=.658, \mathrm{BMI}: \mathrm{p}=.447)$. These patients were seeking treatment for one of several clinical problems including OSA ( $\mathrm{n}=17 ; \mathrm{M}=13 ; \mathrm{F}=4)$, snoring $(\mathrm{n}=5 ; \mathrm{F}=5)$, malocclusion (Anterior Open Bite) $(\mathrm{n}=6 ; \mathrm{M}=3 ; \mathrm{F}=3)$, temporomandibular disorders $(\mathrm{n}=3, \mathrm{~F}=3$ with Open Bite 1$)$, osteoarthritis $(\mathrm{n}=2 ; \mathrm{F}=2)$, minor jaw deformity ( $\mathrm{n}=1$ (M1) myofacial pain with limited opening $(n=1 ; F=1)$, uncomfortable occlusion $(n=1 ; F=1)$, enlarged torus $(n=1 ; M=1)$ and possible mandibular fracture $(n=1 ; M=1)$ at the Tsurumi university dental hospital. It should be noted that none of the patients in our study complained of dysphagia, however, the subset of 17 OSA patients in this group did have a polysomnogram and their mean AHI was $20.9 \pm 12.81$ events/hour, and the 5 snorers had a polysomnogram to rule out OSA (mean AHI $=1.52 \pm 1.30$ ). The other patients did not have polysomnograms and based on clinical interview, they did not exhibit hypersomonlence. The mean (plus one standard deviation) age, height and BMI for our subjects can be seen in Table 1. The age of men ranged from 26 to 80 years. The BMI of males ranged from 19.1 to $28.4 \mathrm{~kg} /$ $\mathrm{m}^{2}$. The age of the females ranged from 24 to 84 years. The BMI of the women ranged from 17.9 to $30.5 \mathrm{~kg} / \mathrm{m}^{2}$.

Baseline descriptive statistics for age and BMI are given in Table 1. Independent t-test results are given in Table 2 comparing men and women's ATV before and after normalizing by patient's height, AT airway volume before and after normalization, and AP and LW of the AT airway. Also Mann-Whitney test results comparing median AT height, and posterior pharyngeal wall volume before and after normalization between male and females are presented in Table 2. This analysis revealed that AT height, ATV and posterior pharyngeal wall volume were found to have a statistically significant gender difference with the men consistently having a larger AT height, ATV and posterior pharyngeal wall volume than the women. However, we could not find a gender difference after normalizing for patient's height. The widest airway lateral width was found to have a statistically significant gender difference with the women having a larger mean LW than the men.

Next we examined the correlation between our normalized variables (ATV/Height and PPWV/Height) with age and BMI (Table 3). In Table 3 what is evident is that ATV/Height increases with increasing age, in both groups, after adjusting for BMI and OSA status. PPWV/Height decreased with increasing age in males and increased with increasing BMI in females. And ATV/Height increased with increasing BMI in males after adjusting for age and OSA status.

\begin{tabular}{|c|c|c|c|c|}
\hline Dependent variable & $\begin{array}{c}\text { Age (unadjusted) } \\
\text { r score } \\
\text { (p value) }\end{array}$ & $\begin{array}{c}\text { Age (BMI \& OSA adjusted) } \\
\text { r score } \\
\text { (p value) }\end{array}$ & $\begin{array}{l}\text { BMI (unadjusted) } \\
\text { r score } \\
\text { (p value) }\end{array}$ & $\begin{array}{c}\text { BMI (Age \& OSA adjusted) } \\
\text { r score } \\
\text { ( } \mathrm{p} \text { value })\end{array}$ \\
\hline \multicolumn{5}{|c|}{ Males only $(\mathrm{n}=19)$} \\
\hline ATV / height $\left(\mathrm{mm}^{2}\right) \dagger$ & $\begin{array}{c}0.438 \\
(\mathrm{p}=.061)\end{array}$ & $\begin{array}{c}0.588 \\
(p=.013)\end{array}$ & $\begin{array}{c}0.384 \\
(\mathrm{p}=.104)\end{array}$ & $\begin{array}{c}0.532 \\
(p=.028)\end{array}$ \\
\hline $\begin{array}{l}\text { Posterior pharyngeal wall / height } \\
\left(\mathrm{mm}^{2}\right) \ddagger\end{array}$ & $\begin{array}{c}-0.625 \\
(p=.004)\end{array}$ & $\begin{array}{c}-0.691 \\
(p=.002)\end{array}$ & $\begin{array}{c}0.311 \\
(\mathrm{p}=.196)\end{array}$ & $\begin{array}{c}0.416 \\
(\mathrm{p}=.096)\end{array}$ \\
\hline \multicolumn{5}{|c|}{ Females only $(\mathrm{n}=19)$} \\
\hline ATV / height $\left(\mathrm{mm}^{2}\right) \dagger$ & $\begin{array}{c}0.687 \\
(p=.001)\end{array}$ & $\begin{array}{c}0.571 \\
(p=.017)\end{array}$ & $\begin{array}{c}0.196 \\
(\mathrm{p}=.422)\end{array}$ & $\begin{array}{c}-0.226 \\
(\mathrm{p}=.383)\end{array}$ \\
\hline $\begin{array}{l}\text { Posterior pharyngeal wall / height } \\
\left(\mathrm{mm}^{2}\right) \ddagger\end{array}$ & $\begin{array}{c}0.020 \\
(\mathrm{p}=.935)\end{array}$ & $\begin{array}{c}-0.302 \\
(\mathrm{p}=.238)\end{array}$ & $\begin{array}{c}0.612 \\
(p=.005)\end{array}$ & $\begin{array}{c}0.700 \\
(p=.002)\end{array}$ \\
\hline
\end{tabular}

$\dagger \mathrm{r}$ score is the Pearson's correlation coefficient or partial correlation

$\ddagger \mathrm{r}$ score is the Spearman's correlation coefficient or partial correlation

Table 3: Simple and partial correlations between anterior tubercle volume and posterior airway wall volume normalized by height, and our covariates age and BMI. Bold values are statistically significant $(\mathrm{p}<0.05)$

Next we examined the correlation between the smallest anterior-posterior diameter and widest lateral width of the airway adjacent to the AT, with ATV and ATV/Height (Table 4). In males, lateral width increased with increasing ATV and ATV/Height (age, BMI and OSA adjusted). However, anterior-posterior diameter decreased with increasing ATV and ATV/Height in females (age, BMI and OSA adjusted).

Our final table examines if BMI and age were predictive of ATV/Height, and PPWV/Height. We conducted linear regressions on age, OSA and BMI (Table 5). In Table 5 what was evident is that age was significantly predictive of ATV/Height in both groups. ATV/Height increases with age in males and females with $44.6 \%$ and $49.8 \%$ of the variability of ATV/Height explained by this model, respectively. Furthermore, ATV/Height increased with increasing BMI in males ( $p=.028)$. In males, PPWV/Height decreases with age $(\mathrm{p}=.007)$ and increases with BMI $(\mathrm{p}=.003)$ with $\mathrm{R}^{2}=63.4 \%(\mathrm{p}=.001)$. In females, we found a significant linear relationship between PPWV/Height and adjusted BMI $(\mathrm{p}=.016)$ with this model explaining $35.1 \%$ of the variability of PPWV/ Height $(\mathrm{p}=.082)$. 


\begin{tabular}{|c|c|c|c|c|}
\hline Dependent variable & $\begin{array}{l}\text { ATV (unadjusted) } \\
\mathrm{r} \text { score } \dagger \\
\quad(\mathrm{p} \text { value })\end{array}$ & $\begin{array}{l}\text { ATV (BMI, age and OSA adjusted) } \\
\text { r score } \ddagger \\
(\mathrm{p} \text { value })\end{array}$ & $\begin{array}{l}\text { ATV/height (unadjusted) } \\
\text { r score } \dagger \\
\text { (p value) }\end{array}$ & $\begin{array}{c}\text { ATV/height (BMI, age and } \\
\text { OSA adjusted) } \\
\text { r score } \ddagger \\
\text { (p value) }\end{array}$ \\
\hline \multicolumn{5}{|c|}{ Males only $(\mathrm{n}=19)$} \\
\hline $\mathrm{AP}(\mathrm{mm})$ & $\begin{array}{c}0.213 \\
(p=.382)\end{array}$ & $\begin{array}{c}0.324 \\
(\mathrm{p}=.221)\end{array}$ & $\begin{array}{c}0.238 \\
(\mathrm{p}=.326)\end{array}$ & $\begin{array}{c}0.391 \\
(\mathrm{p}=.135)\end{array}$ \\
\hline LW (mm) & $\begin{array}{c}0.502 \\
(p=.028)\end{array}$ & $\begin{array}{c}0.632 \\
(p=.009)\end{array}$ & $\begin{array}{c}0.443 \\
(\mathrm{p}=.058)\end{array}$ & $\begin{array}{c}0.615 \\
(p=.011)\end{array}$ \\
\hline \multicolumn{5}{|c|}{ Females only $(\mathrm{n}=19)$} \\
\hline $\mathrm{AP}(\mathrm{mm})$ & $\begin{array}{c}-0.567 \\
(p=.011)\end{array}$ & $\begin{array}{c}-0.607 \\
(p=.013)\end{array}$ & $\begin{array}{c}-0.529 \\
(p=.020)\end{array}$ & $\begin{array}{c}-0.584 \\
(p=.018)\end{array}$ \\
\hline LW (mm) & $\begin{array}{c}-0.327 \\
(\mathrm{p}=.171)\end{array}$ & $\begin{array}{c}-0.183 \\
(\mathrm{p}=.498)\end{array}$ & $\begin{array}{c}-0.352 \\
(\mathrm{p}=.140)\end{array}$ & $\begin{array}{c}-0.198 \\
(\mathrm{p}=.463)\end{array}$ \\
\hline
\end{tabular}

$\dagger \mathrm{r}$ score is the Pearson's correlation coefficient

$\ddagger \mathrm{r}$ score is the BMI-, age- and OSA-adjusted partial correlation

Table 4: Simple and partial correlations between anterior-posterior diameter (AP) and lateral width (LW) of airway (at most anterior tubercle edge) with ATV and ATV/height

\begin{tabular}{|c|c|c|c|c|}
\hline Dependent variable & $\begin{array}{c}\text { Change in dependent variable } \\
\text { by year of age increase } \\
\text { (p value) }\end{array}$ & $\begin{array}{c}\text { Change in dependent variable } \\
\text { by unit of BMI increase } \\
\text { (p value) }\end{array}$ & $\begin{array}{l}\text { Change in dependent } \\
\text { variable if } \mathbf{O S A}=\mathbf{1} \\
\text { ( } \mathrm{p} \text { value })\end{array}$ & $\begin{array}{c}\text { R-square } \\
(\mathrm{p} \text { value of ANOVA F-test)) }\end{array}$ \\
\hline \multicolumn{5}{|c|}{ Males only $(\mathrm{n}=19)$} \\
\hline ATV / height $\left(\mathrm{mm}^{2}\right)$ & $\begin{array}{c}0.002 \\
(p=.013)\end{array}$ & $\begin{array}{c}0.012 \\
(p=.028)\end{array}$ & $\begin{array}{c}-0.045 \\
(\mathrm{p}=.121)\end{array}$ & $\begin{array}{c}44.6 \% \\
(p=.028)\end{array}$ \\
\hline PPWV/ height $\left(\mathrm{mm}^{2}\right)$ & $\begin{array}{c}-0.004 \\
(p=.007)\end{array}$ & $\begin{array}{c}0.028 \\
(p=.003)\end{array}$ & $\begin{array}{c}0.040 \\
(\mathrm{p}=.388)\end{array}$ & $\begin{array}{c}63.4 \% \\
(p=.001)\end{array}$ \\
\hline \multicolumn{5}{|c|}{ Females only $(\mathrm{n}=19)$} \\
\hline ATV / height $\left(\mathrm{mm}^{2}\right)$ & $\begin{array}{c}0.004 \\
(p=.017)\end{array}$ & $\begin{array}{c}-0.006 \\
(p=.383)\end{array}$ & $\begin{array}{c}0.023 \\
(p=.748)\end{array}$ & $\begin{array}{c}49.8 \% \\
(p=.014)\end{array}$ \\
\hline PPWV/ height $\left(\mathrm{mm}^{2}\right)$ & $\begin{array}{c}0.0007 \\
(p=.742)\end{array}$ & $\begin{array}{c}0.023 \\
(p=.016)\end{array}$ & $\begin{array}{c}-0.111 \\
(\mathrm{p}=.258)\end{array}$ & $\begin{array}{c}35.1 \% \\
(p=.082)\end{array}$ \\
\hline
\end{tabular}

Table 5: Linear regression models to predict anterior tubercle volume/height, ATAV/height and PPWV/height per unit of age and BMI increase

\section{Discussion}

Normally, a comparison of the results presented in the paper to prior published results is made to determine if there is consistency or replication of findings (one of Hill's causal criteria). Unfortunately, examining the literature does not produce a directly comparable study. The literature shows that BMI and age are risk factors for OSA and age has been associated with changes in the atlas' height and volume, but increased atlas volume has not been directly examined as a risk factor for a narrowing oropharyngeal airway at the anterior tubercle of atlas region. The aim of our study was to examine the influence of age and BMI on the atlas area and to look for associations between AT height/volume and orpharyngeal airway dimensions.

\section{Differences between genders}

In this study we found a significant difference in AT height and volume and posterior pharyngeal wall volume between men and women, but once we normalized by patient's height, there were no significant differences (Table 2). We feel this adjustment is necessary since even though our subjects were group matched by BMI and age, men still are likely to have bigger vertebrae than women.

\section{Changes with BMI and age}

In this group of BMI- and age-matched Japanese females and males, we found an increase in normalized ATV with age in both genders (Table 5). This seems biologically plausible as osteophytes of the cervical spine are usually seen in elderly adults and when they are particularly prominent, they have been blamed for inducing dysphagia, cough, dysphonia and dyspnea [3-6]. In addition, normalized ATV increased with increasing BMI in males (Tables 3 and 5). In 1971, Julkunen, et al. investigated the relation between hyperostosis and obesity [14]. They performed the following anthropometric measuremens: standing height, weight, and triceps skinfold thickness. One hour after administration of glucose a sample of venous blood was taken to assess the glucose tolerance. X-ray examination of the chest was performed for assessment of the presence of hyperostotic spondylosis. They concluded that the analyses of correlations between glucose tolerance and obesity suggest that decreased glucose tolerance and obesity contribute, in part at least, to the development of hyperostotic spondylosis independently of each other. In our results, 
there was significant correlation between anterior tubercle volume and BMI. In males, the increasing anterior tubercle volume appears as an ossification on attached portion of ligaments or hyperostosis that is associated with obesity. However, we did find that the posterior pharyngeal wall volume decreases significantly with age in males $(\mathrm{p}=.007)$. In 2008, Shigeta, et al. examined the change of the length of the oropharynx airway and the upper oropharyngeal soft tissue volume with age and BMI [15]. They concluded that the upper oropharynx soft tissue significantly decreases with increasing age. However, in males, the lower oropharyngeal soft tissue volume significantly increases with increasing age. Our results correspond to this previous study. We also found in this study an increase of the posterior pharyngeal wall volume with BMI in both groups (Table 5), which is biologically plausible as many studies have found that a loss of weight is correlated with a decrease in the lateral pharyngeal adipose tissue volume [16] and in the volume of the lateral pharyngeal walls [17]. From the results of the previous and this current study, it is suggested that the upper oropharyngeal soft tissue is greatly influenced by age and BMI. Therefore, to reveal gender differences in the relationship between anterior tubercle of the atlas to the adjacent oropharyngeal airway volume, our subjects were matched for age and BMI in the male and female group.

\section{Changes in AP and LW of airway cross-section}

Interestingly for females, the AP dimension of the airway decreases with an increase in AT volume and ATV/Height (after adjusting for age and BMI). This confirms what we have seen in a case report of extremely large osteophytes when the airway is compromised by the anterior tubercle volume. On the contrary, the lateral width was positively correlated in males with ATV and ATV/Height (after adjusting for age and BMI) (Table 4). We suggest that the anterior tubercle compresses the lateral walls so the lateral airway width increases, however we cannot prove this finding or compare to any prior result due to the novelty of this analysis.

\section{Conclusion}

In conclusion, we studied the differences in anterior tubercle of atlas volume (ATV), airway volume and posterior pharyngeal wall volume in males and females and found no significant differences for the patient's height-adjusted data. The data suggests that with age there is an enlargement of ATV in both genders and a decrease in the posterior parapharyngeal wall volume only in males. An increase in BMI will increase the ATV in males and the posterior parapharyngeal wall volume in females. An increase in the ATV (with age for instance) will reduce the anterior-posterior dimension of the airway at C1 (anterior atlas) level, which has been associated with OSA.

\section{Acknowledgement}

Dr. Enciso was partially supported by NIDCR grant \#5 K25 DE016391. No conflicts of interest.

Dr. Ogawa was partially supported by "High-Tech Research Center" Project for Private Universities and grant \# 18390501: matching fund subsidy from MEXT (Ministry of Education, Culture, Sports, Science and Technology). No conflicts of interest.

\section{IRB approval}

The patients gave written consent to participate in this study approved by the Ethics Committee at Tsurumi university dental hospital.

\section{References}

1. Marchiori DM, McLean I, Firth R, Tatum R (1994) A comparison of radiographic signs of degeneration to corresponding MRI signal intensities in the lumbar spine. J Manipulative Physiol Ther 17: 238-45.

2. Shigeta Y, Enciso R, Ogawa T, Shintaku WH, Clark GT (2007) Upper Airway Alterations/Abnormalities in a Case Series of Obstructive Sleep Apnea Patients Identified with Cone-Beam CT. Int J Comput Assist Radiol Surg 2: 402-4.

3. Escobar C, Amores A, Gonzalez Moscoso P, Redondo R (1997) Dysphagia as a symptom of diffuse idiopathic skeletal hyperostosis (Forestier-Rotes disease). A case report and literature review. Acta Otorrinolaringol Esp 48: 161-3.

4. Grasshoff H, Motsch C, Mahlfeld K (1999) Vertebragenic dysphagia. Zentralbl Chir 124: 1041-4.

5. Krause P, Castro WH (1994) Cervical hyperostosis: a rare cause of dysphagia. Case description and bibliographical survey. Eur Spine J 3: 56-8.

6. McGarrah PD, Teller D (1997) Posttraumatic cervical osteophytosis causing progressive dysphagia. South Med J 90: 858-60.

7. Ando E, Ogawa T, Shigeta Y, Hirai S, Ikawa T, et al. (2009) A case of obstructive sleep apnoea with anterior cervical osteophytes. J Oral Rehabil 36: 776-80.

8. Angelos C, Dimitra A (2011) Dysphagia due to anterior cervical osteophytes complicated with hypopharynx abscess. BMJ Case Rep doi: 10.1136/bcr.11.2010.3551.

9. Eyigor H, Selcuk OT, Osma U, Koca R, Yilmaz MD (2012) Cervical osteophytes: a rare cause of obstructive sleep apnea. J Craniofac Surg 23: e444-6.

10. Ando E, Shigeta Y, Nejima J, Yamanaka H, Hirai S, et al. (2015) Assessment of the calcification of the nuchal ligament and osteophytes of the cervical spine in obstructive sleep apnoea subjects and snorers. J Oral Rehabil doi: 10.1111/joor.12354.

11. Kumaresan S, Yoganandan N, Pintar FA, Maiman DJ, Goel VK (2001) Contribution of disc degeneration to osteophyte formation in the cervical spine: a biomechanical investigation. J Orthop Res 19: 977-84.

12. Solow B, Skov S, Ovesen J, Norup PW, Wildschiodtz G (1996) Airway dimensions and head posture in obstructive sleep apnoea. Eur J Orthod 18: 571-9.

13. Shigemoto S, Shigeta Y, Nejima J, Ogawa T, Matsuka Y, et al. (2015) Diagnosis and treatment for obstructive sleep apnea: Fundamental and clinical knowledge in obstructive sleep apnea. J Prosthodont Res 59: 161-71. 
14. Julkunen H, Heinonen OP, Pyörälä K (1971) Hyperostosis of the spine in an adult population. Its relation to hyperglycaemia and obesity. Ann Rheum Dis 30: 605-12.

15. Shigeta Y, Ogawa T, Venturin JS, Nguyen M, Clark GT, et al. (2008) Gender- and age-based differences in computerized tomographic measurements of the oropharynx. Oral Surg Oral Med Oral Pathol Oral Radiol Endod 106: 563-70.

16. Shelton KE, Woodson H, Gay S, Suratt PM (1993) Pharyngeal fat in obstructive sleep apnea. Am Rev Respir Dis 148: 462-66.

17. Welch KC, Foster GD, Ritter CT, Schellenberg JB, Wadden TA, et al. (2002) A novel volumetric magnetic resonance imaging paradigm to study upper airway anatomy. Sleep 25: 532-42.

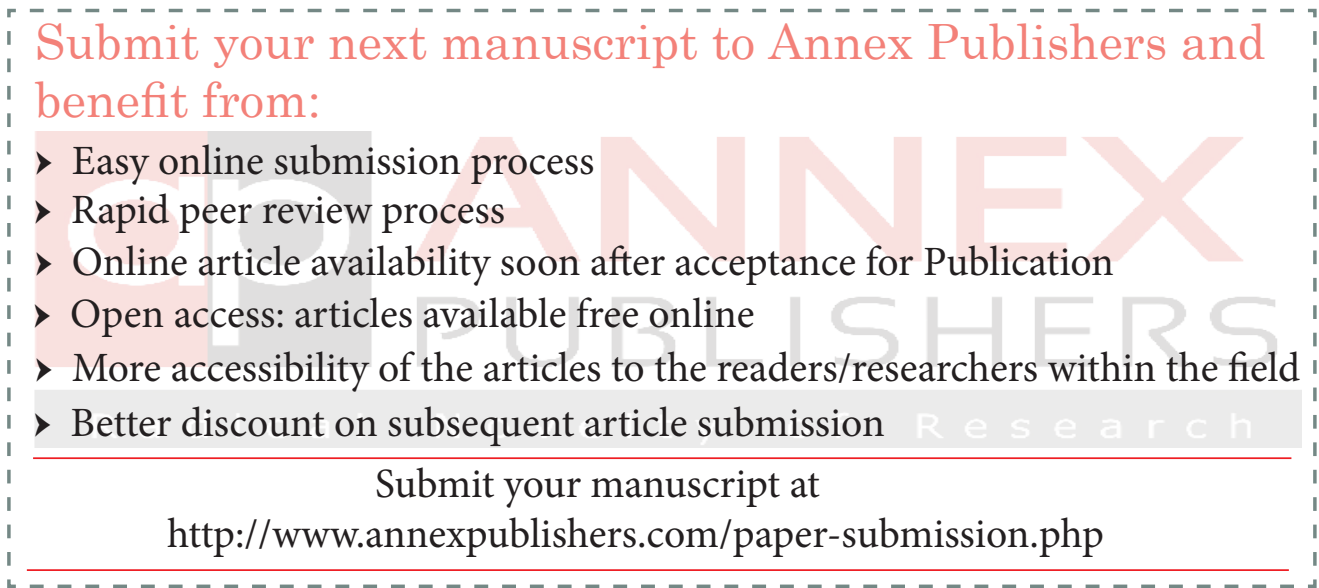

